\title{
A ESPERANÇA: A LEITURA E A ESCRITA DE E PARA MULHERES EM CABO VERDE, 1901
}

\section{Resumo}

Este artigo centra-se no papel da revista $A$ Esperança, publicada como suplemento literário do Almanach Luso-Africano, como lugar da leitura e escrita de e para mulheres. Por esta altura, a escrita e publicações femininas em Cabo Verde já tinham décadas de tradição, sobretudo em revistas e almanaques. Este desenvolvimento histórico rastreia-se na contribuição.

Palavras-chave: Revista «A Esperança», mulheres, Cabo Verde, 1901.

\section{Abstract}

A Esperança: Reading and Writing for and by Women at Cape Verd Islands, 1901

This article is focused on the role of the journal A Esperança, published as literary supplement of the Almanach Luso-Africano, as a place for reading and writing for and by women. At that time, female writing and publishing at the Cape Verd Islands already had decade-long tradition, above all in journals and almanacs. This historical development is retraced in the contribution.

Keywords: Journal «A Esperança», women, Cape Verd Islands, 1901.

\section{Resumen}

A Esperança: Lecturas y escrituras de y para mujeres en Cabo Verde, 1901

Este artículo se centra en el papel de la revista $A$ Esperança, publicada como suplemento literario del Almanach Luso-Africano, como lugar de la lectura y escritura de y para mujeres. Por esta altura, la escritura y publicaciones femeninas en Cabo Verde ya tenían décadas de tradición, sobre todo en revistas y almanaques. Este desarrollo histórico se rastrea en la contribución.

Palabras-clave: Revista «A Esperança», mujeres, Cabo Verde, 1901.

\section{Introdução}

A revista A Esperança: Revista colonial, popular, encyclopédica foi publicada em 1901 com 12 números mensais, como suplemento literário do Almanach Luso-Africano. Por esta altura, a escrita e publicações femininas em Cabo Verde já tinham

* Ibero-Amerikanisches Institut, Stiftung Preußischer Kulturbesitz, Berlim, Alemanha.

Endereço postal: Potsdamer Str. 37, 10785 Berlin, Alemanha.

Endereço eletrónico: musser@iai.spk-berlin.de

ORCID: https: / / orcid.org/0000-0001-9715-3641 
décadas de tradição. A revista surgiu assim numa época em que, após a Conferência de Berlim (1884-1885), o olhar europeu se debruçou mais fortemente sobre África e o continente foi dividido entre as potências europeias. Neste mesmo período, o movimento feminista, em muitos países, reivindicava os mesmos direitos políticos e civis, sobretudo o direito de voto.

Cabo Verde foi a primeira colónia portuguesa em África na qual a impressão do livro fora introduzida, nomeadamente, em 1842 (Oliveira s.d., 2). No final do século XIX as ilhas de Cabo Verde vivenciaram um significativo desenvolvimento literário e cultural. Este desenvolvimento foi sustentado, sobretudo, por descendentes de portugueses que, aliás, viam mesmo em Portugal um local prometedor para a sua carreira intelectual. A metrópole abria-lhes múltiplas possibilidades para divulgar as suas obras e publicar periódicos. A este grupo pertencia, por exemplo, Antónia Gertrudes Pusich (1805-1883), nascida na ilha de São Nicolau, filha do governador de Cabo Verde, tendo sido a primeira mulher a fundar um periódico em Portugal: A assemblea litteraria: jornal de instrucção (Lisboa, 1849-1851).

Para aqueles/as escritores/as que, em Cabo Verde, queriam publicar por si próprios, a imprensa periódica tinha, igualmente, uma extraordinária importância para a divulgação da sua obra. No final do século XIX, havia em Cabo Verde várias sociedades recreativas, grémios literários e várias revistas, algumas das quais, porém, com relativamente pouco tempo de vida. No final do século XIX e início do século XX, foram editados 46 títulos periódicos em território africano de língua portuguesa, nos quais tanto trabalharam europeus como africanos (Santilli 1985, 10). Quanto às publicações cabo-verdianas recorreu-se a impressões, em português e também em crioulo: «já não é, portanto, o homem europeu ou o homem africano que representa essa sociedade, mas o homem crioulo, em cuja maneira de ser as culturas convergentes teceram mais cedo a unidade cultural cabo-verdiana» (Santilli 1985, 28). Esta perspetiva ignora completamente as mulheres cabo-verdianas que, no entanto, tal como muitos testemunhos o confirmam, prestaram uma contribuição significativa para a cultura de Cabo Verde. Embora no país o indigenato não estivesse em vigor como nas outras colónias portuguesas em África e «as representações intelectuais sobre a gênese da nação cabo-verdiana apresentam Cabo verde como o caso paradigmático de anulação de diferenças e desigualdades raciais», importa assinalar que «até fins do século XIX, a sociedade colonizada cabo-verdiana se estruturava sob a dominação racial de uma minoria branca sobre a maioria negra da população» (Anjos 2003, 582).

Durante todo o século XIX manteve-se difícil para autores/as africanos/as colocar um livro seu no mercado literário das respetivas colónias. Nestas, as edições periódicas, ao assumirem um papel significativo, contribuíram decisivamente para a estabilização da literatura que se iria desenvolver (David 2016, 355). Os Almanaques que circulavam em todo o mundo lusófono podem aqui ser considerados como pontos de partida. 


\section{O papel dos Almanaques no século XIX}

Em todo o mundo lusófono, o duradouro Almanach de Lembranças Luso-Brasileiro, editado de 1851 a 1932, tinha grande distribuição. Até 1853 é publicado em Paris e a partir desta data passa a ser publicado em Lisboa, em várias casas impressoras. Havia uma edição portuguesa e outra brasileira que se distinguiam apenas pelos dados do calendário. Já em 1855, o editor do almanaque refere tratar-se de uma edição de 20000 exemplares. Durante todo o tempo de edição, nunca ficou aquém dos 16000 exemplares (David 2016, 356-357). Uma das razões para este sucesso foi o seu módico preço de venda. Como outro fator de sucesso poderão ser considerados os suplementos pertencentes às edições entre 1886 e 1890. Nestes suplementos, eram publicados artigos pertencentes à secção «Variedades» do Almanaque (David 2016, 358). No conjunto total do período de edição do almanaque estavam representados autores dos países africanos de língua portuguesa. Sendo alguns dos textos, inclusivamente, impressos em crioulo, não eram, provavelmente, legíveis nem em Portugal nem no Brasil. É, portanto, plausível que autores/as africanos/as escrevessem aqui para um público africano. $\mathrm{O}$ almanaque permitiu a possibilidade de se chegar a muitos leitores e de contribuir para um desenvolvimento cultural nos respetivos territórios (Chaves 2011, 188).

Alexandre Magno de Castilho anunciou, em 1854, que aceitaria para o almanaque de 1855 quaisquer textos, fossem estes assinados ou anónimos. Logo em 1860 protestaria, no entanto, contra o grande número de maus poemas que lhe tinham sido enviados (Chaves 2011, 189).

Entre os artigos anónimos do almanaque encontravam-se, certamente, os de inúmeras mulheres. Os editores, uma vez que selecionavam o material que deveria ser editado de acordo com o seu próprio gosto, foram criando um novo tipo de autor:

Aquele que não frequenta necessariamente o meio literário ou erudito, que não conhece os meandros do acesso aos editores e à publicação, que não tem necessáriamente uma obra extensa passível de ser reunida em volume, e que para fazer circular as suas produções não precisa necessariamente de declarar o seu nome nem de provar a sua identidade (Anastácio 2012, 67).

Para publicar algo num almanaque era suficiente enviar, simplesmente, um texto por correio postal, na esperança de este ser do gosto do editor. O almanaque constituía, assim, uma porta de entrada para a participação ativa na imprensa periódica e para o reconhecimento do público (Anastácio 2012, 67). Os modelos de comportamento femininos não tinham por isso que ser postos em causa, uma vez que a produção literária poderia ter lugar sem que obrigasse à saída do lar, esfera própria da mulher da alta sociedade, e sem que implicasse lidar com objetos considerados como não femininos. Em altura alguma esta perceção de papéis foi posta 
em causa pela revista $A$ Esperança. Outras revistas do mundo lusófono tematizaram as limitações da mulher à esfera do lar e à sua dependência face ao marido ou ao pai, em parte já no século XIX, tal como Cecília Vieira do Nascimento e Bernardo J. Oliveira o comprovaram: a condição a que estava submetida a mulher brasileira durante o século XIX, de repressão e submissão, era crítica presente no semanário O Sexo Feminino, publicado no Brasil, em Campanha, Minas Gerais (Nascimento e Oliveira 2007, 433). Outras revistas, como A Senhorita, publicada no Brasil de 1910 a 1911, em Curitiba, Paraná, estavam, pelo menos, abertas à publicação de textos feministas (A Senhorita 1910, 5).

No entanto, no século XIX, surgiram também almanaques no mundo de língua portuguesa fundados e editados por mulheres, relativamente aos quais também se pretendia, além do melhoramento do nível geral de educação da mulher, o fomento da sua autonomia financeira e intelectual. Neste contexto, devem ser referidos aqui o Almanach das Senhoras: Portugal e Brazil, fundado por Guiomar Torrezão em 1870 e dirigido, a partir de 1885, por Felismina Torrezão e por Júlia de Gusmão até 1928, assim como o Almanaque das Senhoras Portuenses (1885-1886) e o Almanach das Senhoras Portuguesas e Brazileiras (1885-1887), dirigido por Albertina Paraíso (Anastácio 2012, 68).

O Almanach das Senhoras: Portugal e Brazil foi diretamente inspirado pelo Almanach das Lembranças Luso-Brasileiro, no qual Guiomar Torrezão tinha publicado pela primeira vez, em 1866 (Anastácio 2012, 69). Não foi de modo algum a primeira mulher. Já no ano de 1854 o Almanach de Lembranças Luso-Brasileiro tinha publicado artigos de quatro mulheres, entre os quais um poema de Antónia Gertrudes Pusich, nascida em Cabo Verde. É legítimo colocar aqui a questão de, se por terem vivido parte da sua vida em África, as mulheres se tornavam autoras africanas. Porém, devido às limitações das fontes, é quase impossível determinar até que ponto as autoras se identificavam como portuguesas, africanas ou cabo-verdianas. Para Antónia Gertrudes Pusich, em cuja família se misturaram influências culturais de vários países, a nacionalidade também é pouco consensual, embora haja numerosas fontes sobre a sua vida (cf., entre outros, Talan 2005). Porém, Ana Patrícia Peixinho Vicente Santos parece, claramente, não considerar Antónia Gertrudes Pusich entre as mulheres que se identificavam como africanas, pois escreve que data de 1861 a primeira mulher africana a ter voz num almanaque, nomeadamente Leonor de Sousa e Almeida, de Benguela, em Angola, participando com dois textos em prosa (Santos 2011, 204). Também constata que, além das mulheres nos cinco territórios portugueses em África, participaram igualmente em publicações mulheres brancas da África do Sul. No seu levantamento estatístico conclui que, no Almanaque, foram publicados 24 textos em prosa e 30 poemas de mulheres que viviam em África (Santos 2011, 205). No entanto, nem sempre é possível determinar os nomes daqueles autores e autoras que escreveram sob pseudónimos ou de forma anónima no Almanach de lembranças Luso-Brasileiro. Da mesma maneira, é difícil encontrar uma resposta para a questão da identificação étnica das mulhe- 
res escritoras. Devido às premissas de formação que o trabalho das autoras implicava, é bem provável estas mulheres estarem ligadas a elites sociais e assim à classe dos colonos brancos e dos funcionários coloniais. No entanto, poderá haver aqui também exceções.

A página de Internet com o título Littérature capverdienne. A la découverte d'une culture encore méconnue apresenta o nome ou pseudónimo de doze mulheres de Cabo Verde que publicaram neste almanaque:

- Africana (Maria Luisa de Sena Barcelos): 1883, 1884, 1885, 1886, 1890, 1890 supl.

- Emília dos Mártires Aguiar: 1867

- Humilde Camponesa (Gertrude Ferreira Lima): 1892, 1893, 1894, 1898, 1899

- Uma Desconhecida: 1898, 1899, 1900

- Ida Loff de Fonseca: 1890

- Carlota Lopes: 1891, 1892

- Adele Nobre Martins: 1891, 1892, 1893, 1894, 1896, 1901

- Adelaide Maria das Neves: 1889 supl.

- Antónia Gertrudes Pusich: 1854, 1855, 1856, 1857, 1858, 1859, 1895

- Maria Cristina Rocha: 1913, 1914, 1915, 1916, 1918

- Alda Sales: 1902, 1907, 1908

- Aurélia Teles: 1886, 1887, 1888, 1888 supl., 1889, 1889 supl., 1890 (Littérature capverdienne s.d.).

As mulheres do arquipélago de Cabo Verde estiveram, assim, representadas neste periódico ao longo de décadas. Comparado com o número dos seus colegas masculinos, o das mulheres era relativamente menor.

No próprio Almanach de lembranças... a enumeração de artigos faz-se entre autores e senhoras, ${ }^{1}$ sendo assim um indício de que a atividade das mulheres no almanaque era vista mais como um passatempo do que como uma atividade profissional. Para as mulheres da elite social, esta atividade não estava prevista, a não ser que fosse de caráter caritativo. Aqui e além, vai-se tornando evidente como as autoras se debatem com o papel da mulher das camadas superiores da sociedade. É assim, por exemplo, que uma autora de São Vicente, cujo nome indicado é simplesmente Dona ${ }^{* *}$ descreve o matrimónio como um tipo de negócio e como a única possibilidade de as mulheres ganharem a sua liberdade: «O casamento é o negocio capital da mulher. Porque? Porque ella unindo se a um marido, pelo acaso, pelo calculo, ou pela loucura dos sentidos, faz a conquista plena e inteira da sua liberdade» (Dona** 1891, 378). O preço desta liberdade, que surge simplesmente do cumprimento de normas sociais, subjugando-se a apertados limites, não raramente

Antes da ligeira modificação do nome de Almanach de lembranças luso-brazileiro para Novo Almanach de lembranças luso-brazileiro em 1872, as participações eram estabelecidas entre Cavalheiros e Senhoras (Cardoso e Lousada 2012, 2). 
implicava abdicar da felicidade pessoal, tal como a autora escreve mais à frente: «E o meu viver em amor, murchou nas mãos da tristeza» (Dona** 1891, 378).

\section{O Almanach Luso-Africano}

Após a já longa continuidade do Almanach de Lembranças Luso-Brasileiro sob a participação de autores/as dos dois lados do Atlântico e respetiva circulação de outros almanaques em língua portuguesa, uma outra publicação periódica chamou a atenção dos/das leitores/as e escritores/as em Cabo Verde: o Almanach luso-africano, dado à estampa em duas edições, 1895 e 1899. Segundo o seu editor, o cónego cabo-verdiano António Manuel da Costa Teixeira, este almanaque não deveria ser visto como concorrente do almanaque já há décadas existente, mas como seu complemento e como espaço alternativo, especialmente para os autores africanos verem os seus textos publicados (Carvalho 2011, 56). O objetivo do editor era desenvolver o prazer da leitura, formar o bom gosto e fomentar a divulgação do «espírito africano» (Filho 2011, 15). Em que consistia este último, fica, infelizmente, em aberto, não sendo mais aprofundado. A formação e educação da população cabo-verdiana ${ }^{2}$ era, para Teixeira, um tema grato. Em 1894 fundara a Associação Escolar «Esperança» dedicada a ambos os sexos. Além disso, foi um dos pioneiros na pesquisa da língua em Cabo Verde e um defensor da educação bilingue, em português e em crioulo (Lopes Filho 2011, 16-17).

Manuel da Costa Teixeira resume deste modo o seu programa para o Almanach Luso-Africano: «instruir, educar e recrear» (Teixeira 2011, 8). O almanaque abrangia duas partes: «1.a Noticias diversas sobre tabellas e regulamentos, uteis na vida pratica, e taboas cronologicas. 2.a Miscellanea» (Teixeira 2011: 9). À parte Miscellanea pertenciam, entre muitos outros temas, também a literatura, a educação e a educação pública, assim como informações culturais e económicas. Na parte literária, a maioria dos/das autores/as era de Cabo Verde: das obras poéticas, 30 eram de autores e autoras caboverdianas, 6 de outros/as; dos contos, 11 eram textos cabo-verdianos e 4 de outros autores/as (Carvalho 2011, 69). Cerca de $10 \%$ de todas as contribuições na parte «Miscellanea» era de mulheres de Cabo Verde (Carvalho 2011, 82). Os homens que escreviam para o almanaque eram nomeados como Collaboradores e as mulheres, separadas deste grupo, eram as Collaboradoras (Teixeira 2011, 71-72). Como neste almanaque se indicava a origem dos autores e autoras, pode ser analisada a quantidade de mulheres que escreveram para o Almanach Luso- Africano. Segundo esta análise, nenhuma das autoras declarou ser oriunda da ilha do Fogo, Ilhéu Branco, S. Nicolau, S. Vicente, Sal ou de Santiago. Além disto, as autoras distribuem-se geograficamente da seguinte forma:

2 Uma lei de 20 de setembro de 1844 previa a construção de escolas básicas nas colónias e a construção de uma escola secundária em cada capital de província, porém, quase nada foi posto em prática. 
- Boa Vista: Isménia Lara, 1895, 1899

- Brava: Antónia Pusich, Sara Mendes, Uma desconhecida, (as três) 1899

- Maio: Adelina Cabral Varella, 1899

- Santo Antão: Antónia da Costa, Etelvina Costa, Fortunata da Graça, Humilde Camponesa, Maria da Costa, Mariana Pinto 1895; Antónia da Costa, Etelvina Costa, Fortunata da Graça, Humilde Camponesa, Maria da Costa, Obscura Paulense, 1899.

Cabo Verde foi indicado de forma geral pelas autoras Maria de Carvalho, Uma Sertaneja (ambas 1895), Celestina A.V. Gudual, Esperança de Jesus, Euphrasia Cesaria (todas 1899).

Interseções com o Almanach de Lembranças Luso-Brasileiro dão-se apenas na autora que utilizava o pseudónimo Humilde Camponesa. Comparado com o número de mulheres de Cabo Verde que publicavam no Almanach Luso-Africano e no seu modelo, parece que o acesso das autoras a publicações neste periódico teria sido mais fácil. Talvez a possibilidade de escrever para os próprios conterrâneos e de contribuir para a sua formação tenha também reforçado o interesse em se apresentarem com publicações próprias.

\section{A revista $A$ Esperança}

Após a edição de 1899 do Almanach Luso-Africano, o editor investiu num suplemento literário - a revista $A$ Esperança -, cuja direção partilhou com o cónego Oliveira Bouças, possuindo redações na ilha de São Nicolau e em Braga, Portugal. Na revista $A$ Esperança eram impressos os artigos que tinham sido enviados ao Almanach Luso-Africano, mas que aí tinham acabado por não ser publicados, assim como novos artigos. A revista foi publicada mensalmente durante um ano, e dirigia-se àqueles com poucos recursos financeiros para a compra de livros, jornais e revistas, particularmente a juventude colonial e os professores brasileiros e portugueses do ensino básico (Lopes Filho 2011, 21). O papel que o público leitor desempenhava para a divulgação de novas ideias e conceitos não era de negligenciar. Sobretudo os periódicos constituíam uma referência importante para manifestações literárias e nacionalistas, no século XIX, naqueles que viriam a ser os futuros países africanos de língua portuguesa (David 2016, 353).

Quando A Esperança surgiu, havia já em Cabo Verde, tal como demonstrado, uma certa tradição de leitura e escrita femininas da e na imprensa periódica, à qual pode ser dada continuidade na nova revista sem implicar interrupções. A revista, embora tendo sido concebida como suplemento literário, retoma quase todas as áreas temáticas da «Miscellanea» do Almanach Luso-Africano, das quais faziam parte: 
Sciencia popular - Historia - Geographia - Litteratura - Philosophia - Poesia - Artes - Agricultura elementar e pratica - Ethnographia - Moral - Educação - Musicas (indigenas) - Medicina pratica - Instrucção publica - Composições enigmaticas - Religião - Descripções - Lingua portugueza - Legislação - Biographias - Pensamentos Bibliographia - Industria - Conselhos uteis - Dalectos indigenas - Curiosidades Annuncios (Teixeira 2011: 9).

Esta «Orientação a um conhecimento do saber delineada por uma visão panorâmica, sem restrições disciplinares», é uma das principais características das revistas culturais à volta de 1900 (Frank, Podewski e Scherer 2009, 17). ${ }^{3}$ Todavia, torna-se difícil estipular tipologias para revistas cuja característica mais importante é a diversidade quanto a formatos, periodicidade, objetivos, conteúdos e tudo para um círculo de leitores/as aos quais o/a editor/a se dirige, regra geral, mas não exclusivamente, a uma camada média-alta, sobretudo urbana. A Esperança é a que mais se aproxima das revistas de variedades, uma vez que o seu conteúdo fora pensado mais para o lazer e a formação pessoal do que para debater novos conceitos literários ou culturais.

Compreender os conteúdos da revista $A$ Esperança como «pequeno arquivo» parece-nos, porém, igualmente adequado:

Tais formas organizatórias não integram simplesmente bases de conhecimento heterogéneas, não são «redes» genéricas, «nós» ou «teias de contactos», mas oferecem conhecimento de formas diversas e isso de um modo disposto e sistemático, respetivamente. Conceber a revista literária e cultural como «pequeno arquivo», significa, por um lado, pensá-la como uma entidade em todos os seus fenómenos heterogéneos, baseada, primeiro, num contexto material e pragmático assim como sociológico, possuindo espaços flexíveis e limites. Isto parte do pressuposto de que o conhecimento nunca ocorre somente como uma simples miscelânea, havendo para cada formação regras de expressividade e visibilidade a cumprir (Frank, Podewski e Scherer 2009, 42).

Se se considerar a revista como um pequeno arquivo, obtêm-se numerosos pontos de referência sobre os desenvolvimentos literários e culturais em Cabo Verde, sem, porém, presumir que estes pontos dão um panorama completo da situação. A revista é, assim, uma fonte que pode ser utilizada como ponto de partida para questões concretas sobre cultura e literatura.

É preciso referir, aqui, a nítida intenção do autor de querer contribuir para a instrução dos cabo-verdianos, chamando assim a atenção do próprio arquipélago de Cabo Verde e de África em geral. É com este objetivo que são organizadas rúbri-

\footnotetext{
É de duvidar, porém, que a revista apresentasse firmemente textos feministas, que fossem conformes ao movimento feminista reivindicador dos direitos políticos, uma vez que os textos de e sobre mulheres que a revista $A$ Esperança realmente publicava refletiam os papéis tradicionais femininos da classe média.
} 
cas em $A$ Esperança que transmitem conhecimento do quotidiano da atualidade mundial (Echos Universaes) e outras que informam sobre história, indústria e infraestrutura. O desenvolvimento económico e cultural de Cabo Verde é tematizado através da rúbrica «Poetas Cabo-verdeanos», presente em vários números (3, $5,6,7,11,12)$ da revista e na qual são impressos poemas sobre a história do arquipélago, sem que o nome do autor ou autora seja referido. Estes podem ser classificados como sendo cabo-verdianos, pela referência do país de origem ou até especificamente da ilha, com contribuições literárias de géneros diferentes. Podem encontrar-se em $A$ Esperança mais informações culturais sobre Cabo Verde, tal como a dança Batuque, na ilha de Santiago (Arteaga 1901, 188).

No entanto, também é visível que a revista se posiciona dentro de uma rede, havendo uma «teia de contactos» com outras publicações periódicas da época, que se revela, por exemplo, através da obtenção de artigos e ilustrações de outras revistas.

\section{A Esperança e as mulheres}

Observe-se agora de perto o endereçamento a um público feminino e a participação das mulheres na revista. É surpreendente que, antes de mais, não haja qualquer artigo em $A$ Esperança diretamente dirigido a mulheres ou a um grupo de leitores específico. Pode, portanto, deduzir-se que a intenção do editor ao dar à estampa o periódico seria a de oferecer conteúdos que fossem básica e incondicia onalmente apropriados para todos os potenciais leitores. Ainda assim encontram-se artigos sobre áreas temáticas que, tendencialmente, se enquadram na esfera familiar do lar e no papel que correspondia à mulher da sociedade burguesa na viragem do século XIX para o XX. Dentro desta temática, encontram-se inúmeros conselhos de alimentação e manuseamento dos alimentos, higiene e limpeza de objetos de uso diário. Nos artigos sobre higiene e desinfeção, o modo como lidar com doenças infetocontagiosas e com doentes é, claramente, prioritário, muitas vezes ligado a conselhos como: «A limpêza é o melhor dos remédios contra a doenças e contra os parasitas» (A Esperança 1901a, 168). Nesta mesma linha, vários artigos dão indicações para temas como prevenção de doenças e naturopatia segundo Sebastian Kneipp, assim como conhecimento da medicina popular para, por exemplo, tratamento de dores de dentes (A Esperança 1901b, 165) e extração de verrugas (Scheere 1901, 190). Embora, hoje em dia, estes conselhos nos pareçam completamente ultrapassados, ${ }^{4}$ é clara a intenção de preparar os leitores para evitar problemas de saúde ou para, no caso destes já existirem, saberem curá-los sozinhos. Isto porque, aparentemente, os médicos nem sempre estavam disponíveis a qualquer hora e em qualquer lugar.

$4 \quad$ Como o conselho de não ler na cama (p. 179). 
Uma outra área temática consideravelmente menos extensa é dedicada às crianças e aos jogos infantis, provavelmente com a intenção de ocupar, adequadamente, as crianças pequenas em casa, uma vez que é dada uma explicação rigorosa das regras de certos jogos, como por exemplo:

No jogo do silencio todos os jogadôres devem estar caládos, excepto um, que busca por todos os meios fazer fallar os outros. O que primeiro fálla pága um prenda. Na sua forma mais infantil o que fálla diz a fórmula seguinte: o que québra o silencio é surriádo:

Era não era

No tempo da éra

Trés piolhos dentro d'uma panella.

Trés para ti, trés para ella,

Trés para o primeiro que fallár,

Fora eu, que sou rei de Portugal (Coelho 1901, 109).

Artigos sobre educação e conteúdos didáticos também pertencem aos conteúdos esporádicos de $A$ Esperança. Porém, estes artigos correspondem à intenção do editor de melhorar sustentavelmente o nível de instrução de ambos os sexos no arquipélago de Cabo Verde. Com este propósito eram necessárias decisões políticas, económicas, sociais e conceitos adequados às situações concretas. Não se pode depreender pelos artigos que estes fossem dirigidos especialmente às mulheres.

As áreas temáticas sobre moda e beleza ocupam um espaço reduzido em $A$ Esperança. Um único artigo tem como título «Annuncios de moda» (Vicente 1901, 58). Num outro texto, é aconselhada a receita de uma «pasta para branquear as mãos», que seria basicamente composta de «batatas inglesas» (A Esperança 1901c, 155). Deste anúncio não é difícil fazer a leitura de qual o ideal dominante da sociedade colonial cabo-verdiana, em que o que é branco anda a par com o belo.

É de supor, todavia, que as revistas europeias de moda, especialmente as francesas, que também circulavam na América Latina, teriam, igualmente, as suas leitoras aquando da sua passagem por Cabo Verde.

Uma característica que, tradicionalmente era aplicada, sobretudo, às mulheres - «um dos seus mais penosos atributos», a curiosidade - é objeto de escrita de tendência humorística de um artigo, ao qual também pertencem um conto de Ernesto Gil e uma ilustração, mostrando duas mulheres curiosas (A Esperança 1901d, 73-74). Neste artigo, apesar do tom ser menos sério, é feita a tentativa de cliché patriárquico de um suposto comportamento feminino que nos conduz até Adão e Eva. Este juízo de valor implícito é óbvio: por si só, as mulheres não são capazes de controlar as consequências das suas ações, baseadas na curiosidade, precisando por isso - e não só - de uma liderança masculina. De um modo geral, os textos visam transmitir às leitoras o comportamento social desejado para as mulheres da alta sociedade. 
$\mathrm{O}$ «culto das celebridades», tal como é objeto de repreensão aos estado-unidenses no último número de $A$ Esperança ( $A$ Esperança 1901e, 192), não é, claramente, objeto da revista. A par de alguns artigos sobre proeminentes escritores e políticos assim como dignatários religiosos, significativos para Cabo Verde, constam apenas da rubrica «Echos Universaes» duas mulheres a quem foram dedicados artigos extensos.

Por ocasião do falecimento da rainha Vitória, a 22 de janeiro de 1901, é publicado um obituário, no qual são destacados os seus méritos como rainha e imperatriz, sem deixar de incluir uma curta informação sobre África: «chorada com sinceridade [...] pela perda de sessenta mil subditos que na Africa do sul foram victimas da política imperialista e ambiciosa de Chamberlain e Cecil Rhodes, sonhadores de minas» (A Esperança 1901f, 30). O segundo artigo debruça-se sobre Dona Adelaide de Bragança, viúva de D. Miguel I, que, após a morte do seu esposo, ingressa num convento beneditino, em França, mas que, devido a novas leis sobre ordens religiosas, se vê obrigada a abandonar o país, juntamente com as suas irmãs religiosas (A Esperança 1901g, 142). Significativas são as lacunas que a revista apresenta. Por exemplo, não há nenhum texto sobre mulheres de Cabo Verde, do mesmo modo que nem se focam as mulheres da classe operária, nem de camadas da população de outras classes trabalhadoras. Tal deve ser compreendido como um indício bem claro de qual o círculo de destinatários e destinatárias da revista e dos respetivos interesses explícitos em acontecimentos ligados a membros das elites sociais e das metrópoles europeias.

Os trabalhos que, em $A$ Esperança, são dedicados a pessoas em particular são numerosos. Dão a indicação de que a revista funcionava como fórum de intercâmbio entre os/as autores/as e o público. Também as mulheres pertenciam ao grupo de destinatários das dedicatórias, mas hoje em dia é quase impossível saber a sua identidade ou desvendar as histórias por detrás das dedicatórias. Curioso é aqui, indubitavelmente, a autora que em $A$ Esperança usa o pseudónimo de Obscura Paulense dedicar um dos seus poemas à Humilde Camponeza ${ }^{5}$ (1901a, 107): uma autora que não só publicava no Almanach de Lembranças Luso-Brasileiro como também no Almanach Luso-Africano. Segundo informações da página de Internet Littérature Capverdienne. A la découverte d'une culture encore méconnue, trata-se, em ambos os casos, de pseudónimos da autora, oriunda da ilha de Santo Antão, Gertrude Ferreira Lima (?-1915), cuja biografia é muito pouco conhecida. ${ }^{6}$ Segundo Nuno Catharino Cardoso, a sua instrução escolar decorrera no Colégio das Urselinas, em Coimbra, morando mais tarde, possivelmente, em Lisboa (Cardoso 1917, 157). Seria, certamente, interessante aprofundar estudos sobre esta autora, mas, devido à lacuna de informações para lá da sua obra, são quase impossíveis de concretizar.

Trata-se do poema «O Dictado», adiante mencionado.

$<$ http:/ / www.lirecapvert.org/gertrude-ferreira-limaalias-humilde-camponeza-ou-obscura-paulense-1915.html>. 
Um outro texto em $A$ Esperança é dedicado a uma outra colaboradora da revista, Archangela Brito Afra, que, no texto do seu esposo, J. S. Afra, intitulado «A nossa vida» (J. S. Afra 1901a, 180) é homenageada pelo apoio ao longo de décadas e em que se agradece à Providência por ter conduzido à união de ambos. O mesmo autor dedica um outro artigo, em A Esperança, «a minha nora D. Carlota Rodrigues Afra» (J. S. Afra 1901b, 156). Por sua vez, Archangela Brito Afra dedica o seu artigo em A Esperança, à mãe do editor do Almanach Luso-Africano e, na própria revista, a D. Maria F. C. Teixeira, que, na dedicatória a refere como amiga. A homenageada é descrita como «mãe exemplar, louça d'amor por teu filho dilecto» (A. B. Afra 1901, 172). Também aqui é bem clara a descrição de uma imagem da mulher que a reduz a um papel de apoio emocional, não a mostrando como um ser agente ativo: «a sua divisa é amor e caridade» (Afra 1901, 172). Embora o texto deixe margem para a exceção, para a defesa do próprio filho ela transforma-se numa leoa, o ideal propagado é mais o de comedimento submisso.

Estes exemplos deverão ser suficientes para demonstrar que as redes de contacto pessoais, às quais os membros masculinos e femininos da pequena camada letrada de Cabo Verde se encontravam ligados, desempenharam um grande papel, permitindo fomentar e facilitar um intercâmbio entre Lisboa e as ilhas do Cabo Verde. Também as mulheres tiveram uma participação representativa, mesmo não tendo elas próprias que se apresentar, necessariamente, como autoras.

Em $A$ Esperança, encontra-se um total de oito artigos de mulheres, redigidos por cinco autoras diferentes. ${ }^{7}$ Pelo menos quatro destas eram oriundas de Cabo Verde.

A autora que assina pelo nome de Obscura Paulense está representada com a maioria dos artigos, isto é, quatro. Em 1899, já colaborava para o Almanach Luso-Africano, indicando como sua origem a ilha de Santo Antão. Em A Esperança, está representada com três poemas e um breve diálogo. Dedica cada um dos três poemas ${ }^{8}$ a uma pessoa e um, «As ázas da mãe», designa-o como imitação. Duas das suas contribuições seguem um propósito claramente pedagógico. É o caso do poema $O$ Dictado (Obscura Paulense 1901a, 107) e de A Esmola (Obscura Paulense 1901b 134). Em ambos, trata-se de um diálogo entre mãe e filho. Em O Dictado, o filho recebe a recompensa de uma maçã se não tiver erros no ditado, o que consegue. A mãe escolhe como ditado o texto «Viva Portugal, Nação immortal». A mensagem pedagógica no final do poema é a seguinte:

Ora vês?

O sabêr

dá prazêr,

honradez (Obscura Paulense 1901a, 107).

É claro que é possível que, por entre alguns dos pseudónimos, se escondam outras mulheres.

Os poemas estão nas páginas 7 (Nr.1), 87 (Nr. 6) e 107 (Nr. 7) da revista A Esperança do ano de 1901. 
O facto de a autora selecionar precisamente este texto nacionalista para o ditado pode ser analisado como indício de que há uma identificação com o projeto colonial do Estado português, considerando importante incutir esta posição logo na tenra idade de uma criança branca nas ilhas de Cabo Verde.

A Esmola forma um diálogo entre mãe e filha, no qual a filha conta ter dado uma esmola a um mendigo. A mãe contrapõe, dizendo que, embora tivesse sido um gesto louvável, deveria ter guardado para si o facto de ter dado a esmola. A moral do diálogo termina assim:

Se fizeres algum bem

Não o digas a ninguém (Obscura Paulense 1901b, 134).

Correspondentemente às descrições do papel da mulher nas camadas altas da sociedade, o espírito caritativo das filhas é também percecionado pelas mães de forma inteiramente positiva e louvável. A repreensão acontece, porém, por falar, de todo, sobre o facto, uma vez que contradiz o ideal da mulher de se manter humildemente nos bastidores, sendo o anjo do lar. As intenções da educação, segundo as tradições burguesas do século XIX, tornam-se aqui bem óbvias.

Uma outra autora em A Esperança já tinha colaborado para o Almanach Luso- Africano: Esperança de Jesus. Na revista, está representada com o poema intitulado «Tudo pássa» $(1901,57)$ que tematiza o imperecível de todas as coisas, concluindo que a única coisa perecível é a virtude. Também aqui se revela o intuito pedagógico e o conselho para haver sempre uma reflexão crítica sobre como agir e quais os objetivos que se definem na vida. A terceira colaboradora de Cabo Verde, P. da Graça, está representada numa página com uma charada intitulada «Jogos do Espírito» $(1901,143)$.

Archangela B. Afra está registada como africana, mas o seu artigo vem de Lisboa. Deve, no entanto, considerar-se que tenha vivido parte da sua vida em Cabo Verde. É ela a autora da já citada homenagem a Dona Maria, mãe de António M. da Costa Teixeira.

Por ocasião do falecimento do autor romântico Tomáz Ribeiro, A Esperança publica um louvor em forma de soneto que tinha sido previamente publicado na Chronica. Revista illustrada e litteraria. A revista A Esperança anuncia-o desta forma:

É ainda da 'Chronica' o formosissimo e sentido soneto 'Homenagem a Thomas Ribeiro e á sua illustre familia', escripto por Angelina Vidal uma primorosa escriptora que honra o seu sexo e a língua portugueza e de cuja transcripção pedimos vénia ( $A$ Esperança 1901h, 97).

A escritora e jornalista Angelina Vidal (1853-1917) trabalhou com numerosas revistas em Portugal. Em 1908 publicou também no Almanach de Lembranças Luso- 
-Brasileiro. Esta socialista e republicana também ficou conhecida devido ao seu empenho pelos direitos sociais e direitos da mulher.

Como funcionárias de $A$ Esperança, as mulheres estão representadas em número muito reduzido. Porém, comparativamente, tanto a revista como o almanaque constituem, possivelmente, um local de trabalho de fácil acesso. Especialmente para as mulheres de Cabo Verde, estas duas publicações periódicas ofereciam uma oportunidade para publicar os seus trabalhos e entrar em diálogo com os círculos de leitores.

\section{Balanço}

Quando A Esperança passou a ser publicada, as autoras de Cabo Verde já tinham experiência de ver publicados os seus textos em periódicos cabo-verdianos, mas também além-fronteiras, o que se manifestava especialmente nos almanaques que circulavam no conjunto do mundo lusófono. Os precursores da revista já tinham consolidado, igualmente, vias de intercâmbio entre os autores e autoras e o círculo de leitores, sob a forma de correspondências. Simultaneamente, é de supor que aqueles que escreviam para as revistas no arquipélago de Cabo Verde se conheciam, ou pessoalmente ou através das suas publicações, reagindo reciprocamente às mesmas, inclusive sob a forma de dedicatórias em colaborações específicas. O número de mulheres que publicavam, por volta de 1900, em revistas era significativamente menor do que o número de autores nos mesmos órgãos de publicações, ${ }^{9}$ tanto no mundo lusófono como para além dele. Os periódicos, que já no século XIX tinham sido fundados e dirigidos por mulheres, como o Almanach das Senhoras, de Guiomar Torrezão, ou A Assemblea litteraria, de Antónia Gertrudes Pusich, circulavam, com toda a certeza, também em Cabo Verde. No entanto, a criação de revistas puramente femininas no arquipélago e durante este período nunca teria tido hipóteses de êxito, até pelo reduzido número de potenciais leitoras. Revistas femininas, que apostavam quase exclusivamente na colaboração de mulheres, só vieram a ter êxito nos países de língua portuguesa no século $X X$, como, por exemplo, a revista A Senhorita, editada em 1910/1911, em Curitiba, no Brasil (A Senhorita, 1910-1911).

\section{Referências bibliográficas}

A Esperança. 1901a. «A limpêza é o melhor dos remédios contra a doenças e contra os parasitas.» 11: 168.

A Esperança. 1901b. «Dôr de dentes.» 11: 165.

$9 \quad$ Até ainda no último número do Almanach de Lembranças Luso-Brasileiro de 1932 há 28 contribuições de mulheres contra 259 masculinas (Cardoso e Lousada 2012: 2). 
A Esperança. 1901c. «Pasta para branquear as mãos.» 10: 155.

A Esperança. 1901d. «Curiosidade.» 5: 73-74.

A Esperança. 1901e. «Estados Unidos.» 12: 192.

A Esperança. 1901f. «A rainha Victoria.» 2: 30.

A Esperança. 1901g. «D. Adelaide de Bragança.» 9: 142.

A Esperança. 1901h. «Homenagem a Thomaz Ribeiro.» 7: 97.

A Senhorita. Quinzenario Feminino. 1910-1911. Curitiba: Der Beobachter.

Afra, Archangela B. 1901. «A Mãe.» A Esperança 11: 172.

Afra, J. S. 1901a. «A nossa vida.» A Esperança 12: 180.

Afra, J. S. 1901b. «A Mulher. A minha nora D. Carlota Rodrigues Afra.» A Esperança 10: 156.

Anastácio, Vanda. 2012. "Almanaques. Origem, géneros, produção feminina.» Veredas 18: 53-74.

Anjos, José Carlos Gomes dos. 2003. «Elites intelectuais e a conformação da identidade nacional em Cabo Verde.» Estudos Afro-Asiáticos 25 (3): 579-596. DOI: https: / / doi.org/ 10.1590/S0101-546X2003000300008

Arteaga. António de. 1901. «O Batuque.» A Esperança 12: 188.

Cardoso, Nuno Catharino. 1917. Poetisas portuguesas. Antologia contendo dados bibliograficos et biograficos ácêrca de cento e seis poetisas. Lisboa: Livraria scientifica.

Cardoso, Solange, e Isabel Lousada. 2012. «Mulheres que dão a cara: as senhoras do Almanaque de Lembranças Luso-Brasileiro.» Disponível em https: / / run.unl.pt/handle/ $10362 / 11736$.

Carvalho, Alberto. 2011. «Leitura sociológica.» Almanach Luso-Africano ilustrado para 1895. Edição fac-similada1895, organizado por João Lopes Filho e Alberto Carvalho, 53-106. Edição fac-similada. Coimbra/Lisboa: Almedina/CLEPUL.

Chaves, Vania Pinheiro. 2011. «Notas para o estudo da presença feminina no Almanaque de Lembranças Luso-Brasileiro». Navegações 4 (2): 187-192.

Coelho, T. Adolpho. 1901. «Jogos infantis. O silencio.» A Esperança 7: 109.

David, Debora Leite. 2016. «Almanach de Lembranças: Colaborações africanas no século XIX». Miscelânea. Revista de Literatura e Vida Social 19: 353-368.

Dona**. 1891. «O Casamento.» Novo Almanach de Lembranças Luso-Brazileiro 42: 378.

Frank, Gustav, Madleen Podewski, e Stefan Scherer. 2009. «Kultur - Zeit - Schrift. Literaturund Kulturzeitschriften als 'kleine Archive'.» Internationales Archiv für Sozialgeschichte der deutschen Literatur 34 (2): 1-45. DOI: https: / / doi.org/10.1515/iasl.2009.013

Graça, P. da. 1901. «Jogos do Espírito.» A Esperança 9: 143.

Jesus, Esperança. 1901. «Tudo pássa.» A Esperança 4: 57.

Lopes Filho, João. 2011. "Cónego António Manuel da Costa Teixeira.» In Almanach Luso-Africano ilustrado para 1895, organizado por João Lopes Filho e Alberto Carvalho, 9-52. Edição fac-similada. Coimbra/Lisboa: Almedina/CLEPUL.

Littérature Capverdienne. s.d. «Almanachs». Littérature Capverdienne. Disponível em http: / / www.lirecapvert.org/almanachs.html [Consultado em 10 de agosto de 2018].

Nascimento, Cecília Vieira do, e Bernardo J. Oliveira. 2007. «O Sexo Feminino em campanha pela emancipação da mulher.» Cadernos Pagu 29: 429-457. DOI: https: / / doi.org/10.15 90/S0104-83332007000200017

Obscura Paulense. 1901a. «O Dictado.» A Esperança 7: 107.

Obscura Paulense. 1901b. «A Esmola.» A Esperança 9: 134.

Oliveira, Jurema José de. s.d. «As Literaturas africanas e o jornalismo no período colonial.» Disponível em http: / / www.omarrare.uerj.br/numero8/pdfs/jurema.pdf [Consultado em 30 de dezembro de 2018].

Santilli, Maria Aparecida. 1985. Estórias africanas. História \& Antologia. São Paulo: Ática. 
Santos, Ana Patrícia Peixinho Vicente. 2011. «A mulher de África no Almanaque de Lembranças Luso-Brasileiro.» Navegações 4 (2): 204-207.

Scheere, Dr. 1901. «Contra as verrugas.» A Esperança 12: 190.

Talan, Nikica. 2005. «Antónia Gertrudes Pusich: pioneira do jornalismo feminino em Portugal.» Brotéria 161 (4, 5, 6,): 225-241, 353-365, 455-472.

Teixeira, Manuel da Costa, dir. 2011. Almanach Luso-Africano ilustrado para 1895, organizado por João Lopes Filho e Alberto Carvalho. Edição fac-similada. Coimbra/Lisboa: Almedina/CLEPUL.

Vicente, S. 1901. «Annuncios de moda.» A Esperança 4: 58.

Ricarda Musser. Romanista. Doutorada em Culturas Românicas pela Universidade Humboldt de Berlim e Mestre em Ciências de Informação da mesma universidade, é colaboradora do Ibero-Amerikanisches Institut PK (Instituto Ibero-Americano, IAI) em Berlim. Tem trabalhado em projetos de investigação sobre a digitalização como modo de mobilização de objetos, revistas culturais latinoamericanas e culturas populares ibero-americanas. É curadora das coleções lusófonas, chilenas e mexicanas da biblioteca do IAI.

Endereço eletrónico: musser@iai.spk-berlin.de

Artigo recebido a 26 de janeiro de 2019 e aceite para publicação em 29 de março de 2019. 